\title{
SHORT-COURSE THROMBOLYSIS AS THE FIRST LINE OF THERAPY FOR CARDIAC VALVE THROMBOSIS
}

\author{
Rosa Manteiga, $\mathrm{MD}^{\mathrm{a}}$ \\ Juan Carlos Souto, MD \\ Albert Altès, $\mathrm{MD}^{\mathrm{a}}$ \\ Jose Mateo, MD \\ Alejandro Arís, $\mathrm{MD}, \mathrm{PhD}^{\mathrm{b}}$ \\ José $\mathrm{M}^{\mathrm{a}}$ Dominguez, $\mathrm{MD}^{\mathrm{c}}$ \\ Xavier Borrás, $\mathrm{MD}^{\mathrm{c}}$ \\ Francesc Carreras, $\mathrm{MD}^{\mathrm{c}}$ \\ Jordi Fontcuberta, MD, $\mathrm{PhD}^{\mathrm{a}}$
}

\begin{abstract}
Objective: To retrospectively evaluate the clinical and echocardiographic criteria of thrombolytic therapy for mechanical heart valve thrombosis. Methods: Nineteen consecutive patients with 22 instances of prosthetic heart valve thrombosis (14 mitral, 2 aortic, 3 tricuspid, and 3 pulmonary) were treated with short-course thrombolytic therapy as first option of treatment in absence of contraindications. The thrombolytic therapy protocol consisted of streptokinase $(1,500,000 \mathrm{IU}$ in 90 minutes $)(n=18)$ in one $(n=7)$ or two $(n=11)$ cycles or recombinant tissue-type plasminogen activator (100 mg in 90 minutes) $(n=4)$. Results: Overall success was seen in $82 \%$, immediate complete success in $59 \%$, and partial success in $23 \%$. Six patients without total response to thrombolytic therapy underwent surgery, and pannus was observed in $83 \%$. Six patients showed complications: allergy, stroke, transient ischemic attack, coronary embolism, minor bleeding, and one death. At diagnosis, 10 patients evidenced atrial thrombus by transesophageal echocardiography, 3 of whom experienced peripheral embolism during thrombolysis. Four episodes of rethrombosis were observed (16\%). The survivorship was $84 \%$ with a mean follow-up of 42.6 months. Conclusions: A short-course of thrombolytic therapy may be considered first-line therapy for prosthetic heart valve thrombosis. The risk of peripheral embolism may be evaluated for the presence of atrial thrombus by transesophageal echocardiography at diagnosis. (J Thorac Cardiovasc Surg 1998;115:780-4)
\end{abstract}

D espite the improvements in the design of prosthetic heart valves and the use of anticoagulation, systemic embolism and valve thrombosis remain the most dreaded complications of mechanical heart valve replacement. ${ }^{1}$

In 1982 the reported incidence of obstructive prosthetic heart valve thrombosis (PHVT) ranged from $0.5 \%$ to $6 \%$ per patient-year in the aortic and mitral valve position ${ }^{2}$ to as high as $20 \%$ in the tricuspid

From the Thrombosis and Hemostasis Unit, ${ }^{a}$ Cardiac Surgery and Cardiology ${ }^{\mathrm{c}}$ Departments, Hospital de la Sta Creu i St Pau, Barcelona, Spain.

Presented at the Thirteenth International Congress on Fibrinolysis and Thrombolysis, June 1996.

Received for publication July 18, 1997; revisions requested Sept. 2, 1997; revisions received Sept. 29, 1997; accepted for publication Sept. 30, 1997.

Address for reprints: J. Fontcuberta, MD, PhD, Departament d'Hematologia, Unitat d'Hemostasia i Trombosi, Hospital de la Santa Creu I Sant Pau, Antoni Ma Claret 167, 08025 Barcelona, Spain.

Copyright (C) 1998 by Mosby, Inc.

$0022-5223 / 98 \$ 5.00+0 \quad \mathbf{1 2 / 1 / 8 6 5 2 2}$ position. ${ }^{3}$ These rates, however, have been largely reduced with the new models of prosthetic valves $(4 \%){ }^{4}$ Although operation has classically been the standard procedure, ${ }^{4-7}$ it implies a high mortality $(8 \%$ to $60 \%$ ), especially in New York Heart Association (NYHA) functional class III and IV, which is the most frequent at diagnosis. Since Luluaga and colleagues ${ }^{8}$ first reported successful treatment of tricuspid PHVT with streptokinase, numerous cases of thrombolytic therapy (TT) have been reported, ${ }^{9-20}$ with success rates of $70 \%$ to $89 \%$. The precise role of thrombolysis for the management of PHVT is not well defined, however, and its clinical and echocardiographic criteria are still debated. We have used a short course of TT as our primary mode of therapy for PHVT since January 1984 and have collected data on our results retrospectively. The purpose of this report is to analyze our experience with medical management of PHVT during a 13-year period.

\section{Methods}

From January 1984 to January 1997, 19 patients with PHVT were treated with TT on 22 occasions in our center 
Table I. Clinical characteristics of thrombolytic therapy (TT) episodes

\begin{tabular}{|c|c|c|c|c|c|c|c|}
\hline $\begin{array}{l}\text { Case } \\
\text { No. }\end{array}$ & Age/sex & $\begin{array}{l}\text { Years after } \\
\text { operation }\end{array}$ & $\begin{array}{l}\text { Valve } \\
\text { position }\end{array}$ & $\begin{array}{c}\text { Symptoms-TT } \\
\text { (days) }\end{array}$ & NYHA & $I N R$ & ECHO \\
\hline 1 & $47 / \mathrm{M}$ & 18 & $\mathrm{~T}$ & 30 & II & $\mathrm{O}$ & TTE \\
\hline 2 & 70/M & 5 & Ao & 91 & I & $\mathrm{O}$ & TTE \\
\hline 3 & $47 / \mathrm{F}$ & 11 & M & 92 & II & $\mathrm{SO}^{*}$ & TEE \\
\hline 4 & $31 / \mathrm{F}$ & 6 & $\mathrm{P}$ & 91 & III & SO & TTE \\
\hline 5 & $47 / \mathrm{M}$ & 15 & M & 20 & IV & SO & TTE \\
\hline 6 & $51 / \mathrm{M}$ & 3 & M & 19 & $\mathrm{I} \dagger$ & $\mathrm{O}$ & TEE \\
\hline 7 & $63 / \mathrm{F}$ & 5 & M & 13 & IV & SO & TEE \\
\hline 8 & $61 / F$ & 2 & M & 6 & III & $\mathrm{SO}^{*}$ & TEE \\
\hline 9 & $35 / F$ & 6 & M & 2 & IV & SO* & TTE \\
\hline 10 & $46 / \mathrm{F}$ & 17 & M & 14 & IV & $\mathrm{O}$ & TEE \\
\hline 11 & $45 / F$ & 0.2 & M & 4 & IV & $\mathrm{SO}^{*}$ & TTE \\
\hline 12 & $65 / \mathrm{F}$ & 0.4 & M & 15 & $\mathrm{I} \dagger$ & SO & TEE \\
\hline 13 & $71 / \mathrm{F}$ & 7 & M & 30 & IV & $\mathrm{SO}^{*}$ & TEE \\
\hline 14 & $57 / \mathrm{F}$ & 0.8 & Ao & 15 & III & SO & TTE \\
\hline 15 & $51 / \mathrm{F}$ & 0.3 & $\mathrm{~T}$ & 33 & IV & SO & TEE \\
\hline 16 & $45 / F$ & 10 & M & 4 & IV & SO & TEE \\
\hline 17 & $24 / F$ & 9 & $\mathrm{P}$ & 276 & I & SO & TTE \\
\hline 18 & $31 / \mathrm{F}$ & 8 & M & 7 & III & $\mathrm{SO}^{*}$ & TEE \\
\hline 19 & $35 / \mathrm{F}$ & 9 & $\mathrm{P}$ & 7 & I & $\mathrm{O}$ & TTE \\
\hline 20 & $61 / \mathrm{F}$ & 0.02 & M & 1 & IV & SO & TTE \\
\hline 21 & $43 / \mathrm{F}$ & 10 & M & 34 & III & $\mathrm{O}$ & TEE \\
\hline 22 & $51 / \mathrm{F}$ & 0.6 & $\mathrm{~T}$ & 1 & III & $\mathrm{O}$ & TEE \\
\hline
\end{tabular}

Ao, Aortic; $E C H O$, echocardiography performed for diagnosis; INR, anticoagulation level in the 3 months preceding valvular thrombosis; $M$, mitral; $N Y H A$, functional class at diagnosis; $O$, optimal; $P$, pulmonar; SO, suboptimal; $T$, tricuspid; TEE, transesophageal echocardiography; TTE, transthoracic echocardiography.

*Acenocumarol was stopped and switched to heparin within the previous month as preparation for elective surgery or pregnancy.

$\dagger$ Peripheral embolism

(three rethrombosis) (Tables I and II). To give an idea of the incidence of this complication, 2096 mechanical heart valves were inserted in our institution during the same period (1698 tilting disk valves and 398 bileaflet valves), with a total of 1148 patients with mechanical heart valves following monthly international normalized ratio (INR) controls. Currently, we recommend that our mechanical valve patients be maintained on acenocoumarol, adjusted to maintain the INR at 2 to 3 for aortic and 2.5 to 3.5 for tricuspid and mitral prosthesis.

PHVT diagnosis was made by a combination of clinical data (heart failure, absence of prosthetic sounds), fluoroscopic examination (abnormal mobility of tilting disks), and transthoracic Doppler echocardiographic abnormalities (high prosthetic gradient, lack of mobility). In 12 cases a complementary transesophageal echocardiography (TEE) was performed to disclose the presence of a large periprosthetic nonobstructive thrombus. TEE enabled us to visualize 10 cases of paraprosthetic thrombi, all of them in the atrial side of mitral or tricuspid prosthesis. Maximal thrombus size was measured in cases in which TEE was performed (Table II). Both TEE and transthoracic Doppler echocardiography were performed in each patient before and 24 hours after TT in accordance with previously described standard projections. ${ }^{21-23}$

Total response to TT was defined as return to the NYHA functional class before the PHVT on the basis of clinical and echocardiographic findings (return to normality of transvalvular gradient). Partial response to TT was defined as an improvement in the transvalvular gradient $>50 \%$ even though status before PHVT was not reached.

Since January 1984, we have used a short course of TT in all patients with PHVT, provided that the patient had no contraindications for TT. Streptokinase was given in 18 cases according to the same protocol recommended for treatment of myocardial infarction (loading dose 250,000 IU in 20 minutes followed by 1,500,000 IU in 90 minutes). Recombinant tissue-type plasminogen activator (rt-PA), loading dose $10 \mathrm{mg}$ followed by $90 \mathrm{mg}$ for 90 minutes, was the fibrinolytic agent used in the remaining four cases. The choice of rt-PA was due to use of streptokinase in previous PHVT episodes. In 11 cases a second cycle of streptokinase was administered when a partial response was achieved with the first course. Heparin infusion was introduced after the fibrinolytic treatment when the fibrinogen level was greater than $0.5 \mathrm{gm} / \mathrm{L}$ and was continued for 7 to 10 days to obtain a partial thromboplastin time at least twice the control value. It was then replaced by acenocoumarol adjusted to obtain optimal INR values.

Changes in the incidence of events were analyzed by Fisher's exact probability test.

\section{Results}

The clinical characteristics of the patients are presented in Table I using NYHA criteria. The study group consisted of 15 women and 4 men, with 
Table II. Outcome of thrombolytic therapy (TT) courses

\begin{tabular}{|c|c|c|c|c|}
\hline $\begin{array}{c}\text { Case } \\
\text { No. }\end{array}$ & $\begin{array}{l}\text { Paraprosthetic } \\
\text { thrombus size } \\
(\mathrm{mm})\end{array}$ & $T T$ & Result & Complication \\
\hline 1 & $\mathrm{~N}$ & SK & $\mathrm{F}$ & $\mathrm{N}$ \\
\hline 2 & $\mathrm{~N}$ & SK & TR & $\mathrm{N}$ \\
\hline 3 & 7 & SK & $\mathrm{F}$ & Allergy \\
\hline 4 & $\mathrm{~N}$ & SK & TR & $\mathrm{N}$ \\
\hline 5 & $\mathrm{~N}$ & SK & TR & $\mathrm{N}$ \\
\hline 6 & 6 & SK & PR & Stroke \\
\hline 7 & 8 & SK & PR & $\mathrm{N}$ \\
\hline 8 & 7 & SK & TR & $\mathrm{N}$ \\
\hline 9 & $\mathrm{~N}$ & SK & $\mathrm{F}$ & Death \\
\hline 10 & 6 & r-TPA & TR & $\mathrm{N}$ \\
\hline 11 & $\mathrm{~N}$ & SK & PR & $\mathrm{N}$ \\
\hline 12 & 15 & SK & TR & TIA \\
\hline 13 & 6 & SK & TR & Minor bleeding \\
\hline 14 & $\mathrm{~N}$ & SK & TR & $\mathrm{N}$ \\
\hline 15 & 35 & SK & $\mathrm{TR}$ & $\mathrm{N}$ \\
\hline 16 & $\mathrm{~N}$ & SK & TR & $\mathrm{N}$ \\
\hline 17 & $\mathrm{~N}$ & SK & $\mathrm{F}$ & $\mathrm{N}$ \\
\hline 18 & 4 & SK & TR & Coronary embolism \\
\hline 19 & $\mathrm{~N}$ & r-TPA & TR & $\mathrm{N}$ \\
\hline 20 & $\mathrm{~N}$ & r-TPA & PR & $\mathrm{N}$ \\
\hline 21 & $\mathrm{~N}$ & SK & PR & $\mathrm{N}$ \\
\hline 22 & 32 & r-TPA & TR & $\mathrm{N}$ \\
\hline
\end{tabular}

$F$, Failure; $N$, none; Paraprosthetic maximal thrombus size evidenced by transesophagic echocardiography; $P R$, partial response; $r-T P A$, recombinant tissue-type plasminogen activator; $S K$, streptokinase; $T I A$, transient ischemic attack; $T R$, total response.

a mean age at first thrombotic episode of 49 years (range 24 to 72 years). The presenting symptoms were heart failure as a result of valve obstruction in 18 cases (9 in NYHA functional class IV, 6 in NYHA class III, 3 in NYHA class II), non-central nervous system peripheral embolism in 2 cases, and absence of prosthetic sounds in the remaining 2 cases (NYHA class I). Consequently, 15 patients were NYHA class III and IV (68\%) and 7 were NYHA class I and II (32\%).

We evaluated the anticoagulation level with acenocoumarol by INR in the 3 months preceding the thrombotic episode, and we observed that $68 \%$ of patients had suboptimal levels. In six patients acenocoumarol was stopped within the previous month as preparation for elective surgery or pregnancy.

The valves involved were 13 tilting disk prostheses (12 Björk-Shiley [Shiley, Inc., Irvine, Calif.], 1 Omniscience [Medical Inc., Inver Grove Heights, Minn.]) and 9 bileaflet (3 St. Jude Medical [St. Jude Medical, Inc., St. Paul, Minn], 5 Carbomedics [CarboMedics, Inc., Austin, Tex.], 1 Duromedics [Hemex Scientific Inc., Austin, Tex.]).

The mean time elapsed from valve replacement to the first thrombotic episode was 72 months (range 3 to 216 months). The mean time of duration of symptoms was 42 days (range 1 to 276 days). In three patients fibrinolysis was used in the recent postoperative period (between 20 and 60 days after surgery).

In our center the incidence of mechanical heart valves inserted during the period of study was equal regarding sex, but we found a higher incidence of PHVT in women. Only two of these women had PHVT risk factors (both were pregnant).

Fibrinolytic treatment was successful (with one or two cycles of treatment) in 18 cases $(82 \%)$. Total response was achieved in 13 patients (59\%) and partial in 5 patients $(23 \%)$.

Six patients without total response to TT underwent surgery for valve replacement without mortality and with evidence of pannus in five valves (83\%).

Three patients presented a total of four episodes of thrombosis recurrence (18\%), at a mean of 12 months after the first thrombotic episode (range 1 to 39 months). A total response was achieved in the three cases treated again with TT.

No major hemorrhagic events were observed. Major adverse events were embolic episodes. Systemic embolisms were observed in three cases (19\% of left-sided valves): One case of embolic stroke with partial recuperation, one episode of transient ischemic attack, and one case of coronary embolism with total recuperation. All the embolic episodes occurred early during the first fibrinolytic infusion. TT in the first case was discontinued at the beginning of infusion because of the suspicion of brain hemorrhage, although posterior brain scanning confirmed ischemic stroke. At diagnosis, 10 patients had evidence of atrial thrombus by TEE and 3 of them experienced peripheral embolism; all cases were in atrial fibrillation. Embolism was more frequent in patients in functional class IV (two of the cases).

A pregnant woman with mitral PHVT in pulmonary edema died early because of TT failure. Necropsy was not performed.

Other minor complications of TT were one case of minor peripheral bleeding associated with vascular injury that did not require blood transfusion, and one case of self-limiting allergy.

The statistical analysis showed no significant differences in success rates in relation with valve type (bileaflet prostheses vs single tilting disk valves) and valve position.

Follow-up consisted of clinical examination and echocardiography performed at three monthly intervals to exclude any thrombotic recurrence. Sixteen 
Table III. Principal series reported of thrombolytic therapy (TT) for prosthetic heart valve thrombosis

\begin{tabular}{|c|c|c|c|c|c|}
\hline Author & Cases & Indication $T T$ & $\begin{array}{c}\text { Success } \\
\text { rate }\end{array}$ & Embolism & Hemorrhage \\
\hline Witchitz et $\mathrm{al}^{9}$ & 13 & First option & $70 \%$ & $\mathrm{~N}$ & 1 \\
\hline Kurzrok et $\mathrm{al}^{12}$ & 41 & Vble. & $78 \%$ & $15 \%$ & 5 \\
\hline Martinell et al ${ }^{14}$ & 6 & NYHA III-IV & $67 \%$ & 1 & NR \\
\hline Roudaut et $\mathrm{al}^{15}$ & 75 & NYHA III-IV & $75.6 \%$ & $24 \%$ & 1 \\
\hline Silber et $\mathrm{al}^{17}$ & 10 & First option & $80 \%$ & $\mathrm{~N}$ & 4 \\
\hline Vitale et $\mathrm{al}^{18}$ & 8 & NYHA I-II & $100 \%$ & 1 & $\mathrm{~N}$ \\
\hline Reddy et al ${ }^{19}$ & 44 & NHYA III-IV & $88.6 \%$ & 1 & 3 \\
\hline Manteiga et al & 22 & First option & $82 \%$ & $19 \%$ & $\mathrm{~N}$ \\
\hline
\end{tabular}

$N$, None; $N Y H A$, functional class; $N R$, not reported; Vble, compiled cases.

patients were surviving (84\%) with a mean time of follow-up of 42.6 months.

\section{Discussion}

Massive thrombosis of a prosthetic heart valve is always a life-threatening event. The reported operative mortality ranges between $8 \%$ and $60 \% .^{3,5-7}$ In 1983 Husebye and colleagues ${ }^{6}$ reported 552 patients undergoing 617 reoperations for repair or replacement of a prosthetic heart valves and noted an operative mortality of $5.9 \%$ for repeat aortic and $19.6 \%$ for repeat mitral valve replacement. They also showed that surgical risk was related to the preoperative functional class and the urgency of the procedure; patients in NYHA functional class III and IV had a mortality risk ranging from $6 \%$ to $41 \%$; urgent procedures had a mortality of $8 \%$ to $20 \%$, and that for emergency procedures was $37 \%$ to $55 \%$. In contrast, patients in functional classes I and II and those undergoing elective procedures had a mortality of only $0 \%$ to $4 \%$, similar to that of the original operation. Several other investigators reported mortality rates in agreement with that of Husebye and colleagues and confirmed the correlation between mortality and advanced NYHA functional class at the time of operation.

Since 1980, numerous series of TT have been reported for PHVT $^{9-20}$ (Table III), with success rates ranging from $70 \%$ to $100 \%$ and the principal complication of TT being peripheral embolism. However, in the largest series reported TT has been used not as first-line treatment for PHVT but only in patients in advanced NYHA functional class (III to IV), assuming that the risk of peripheral embolism with permanent neurologic damage was lower than the surgical risk. In these series the second risk of TT was major hemorrhagic complications, although in all cases the TT infusion time was at least 12 hours (range 12 to 112 hours). To our knowledge, no large series of TT as first-line treatment for PHVT has been reported.
Because most patients with PHVT in our center were in NYHA class III and IV at diagnosis, we chose a short course of TT as the first option of treatment of PHVT to achieve a fast clinical response and to reduce the bleeding risk. This course of TT with infusion of streptokinase in only 90 minutes demonstrated an overall success rate similar to that in previously reported standard protocols as evidenced by the presence of pannus in $83 \%$ of the cases without total response to TT. In fact, three of the four cases with TT failure had symptoms of long duration (30, 92, and 276 days) (see Tables I and II), suggesting that the underlying pannus and/or organized thrombus could have caused TT resistance. Because TT was more successful in NYHA class III and IV, this short course of TT is probably warranted in this group and it is also probable that TT may allow operation in a more stable clinical setting, if needed.

The reported incidence of major hemorrhagic events with TT is $6 \% .{ }^{20}$ We did not find major hemorrhagic complications that could be related to the short course of TT, although this excellent result must be interpreted with caution in such a small sample size.

The major risk is embolism, probably caused by fragmentation of the thrombus. Peripheral embolism occurred in three cases (19\% of left-sided prostheses), all of them with a periprosthetic thrombus demonstrated at TEE study. Two patients experienced total recuperation; in the third patient the permanent neurologic damage was probably related to the discontinuation of the infusion of streptokinase because of suspected brain hemorrhage. Thus it seems that after TT, most patients with a thrombosed prosthesis in the left side of the heart will not have permanent neurologic sequelae caused by systemic embolization. These data are also in accordance with observations of patients receiving urokinase for left ventricular thrombus after acute myocardial infarction. ${ }^{24}$ 
TEE is a reliable method in the detection of paravalvular thrombosis, particularly in the nonobstructive forms and can therefore be helpful in deciding wether a patient with prosthetic thrombosis should be treated according to the size of the thrombus. ${ }^{25}$

According to our experience and the review of the literature, it appears that TT may be considered first-line therapy for prosthetic heart valve occlusion. Patients in NYHA functional classes I and II achieved best results, with the lowest incidence of peripheral embolism, and no cases of peripheral embolism with permanent neurologic damage were observed. TT may be recommended in patients in NYHA functional class III and IV on diagnosis of PHVT because, although the success rate is lower and the incidence of complications is higher, such patients form the subgroup with the highest operative mortality risk. TEE must be considered a reliable method for the diagnosis of PHVT because at the same time it may evaluate the risk of peripheral embolism.

This is a retrospective study on our experience in 22 PHVT episodes in 19 patients undergoing TT over the last 13 years. However, it has the advantages of being the largest single-center series of patients treated with a short course of TT for PHVT as first-line treatment with diagnosis by TEE in most cases.

\section{Conclusions}

Efficacy of short-course TT was comparable with that of standard protocols and was the same for NYHA III and IV as for NYHA I and II. We believe this TT protocol should be considered first-line therapy for PHVT. TT may be dangerous in the presence of left-sided atrial thrombosis, but the risk of peripheral embolism may be evaluated by TEE.

\section{REFERENCES}

1. Vongpatanasin W, Hillis D, Lange RA. Prosthetic heart valves. N Engl J Med 1996;335:407-16.

2. Edmunds LH. Thromboembolic complications of current cardiac valvular prosthesis. Ann Thorac Surg 1982;34:96-104.

3. Thorburn CW, Morgan JJ, Shanaban MX, Chang VP. Longterm results of tricuspid valve replacement and the problem of prosthetic valve thrombosis. Am J Cardiol 1983;51:1128-32.

4. Akins CW. Results with mechanical cardiac valvular prostheses. Ann Thorac Surg 1995;60:1836-44.

5. Alveraz-Ayuso L, Juffe A, Rufilanchas JJ, Babin F, Burgos R, Figuera D. Thrombectomy: surgical treatment of the thrombosed Björk-Shiley prosthesis. J Thorac Cardiovasc Surg 1982;84:906-10.

6. Husebye DG, Pluth JR, Piehler JM, Schaff HV, Orszulak TA, Puga FJ, et al. Reoperation on prosthetic heart valves: an analysis of risk factors in 552 patients. J Thorac Cardiovasc Surg 1983;86:543-52.

7. Deviri E, Sareli P, Wisenbaught T, Cronje S. Obstruction of mechanical heart valve prostheses: clinical aspects and surgical management. J Am Coll Cardiol 1991;17:646-50.

8. Luluaga IT, Carrera D, D'Oliveira J, Cantaluppi CG, Santin H, Molteni L. Successful thrombolytic therapy after acute tricuspid valve obstruction [letter]. Lancet 1971;1:1067-8.

9. Witchitz S, Veyrat C, Moisson P, Scheiman N, Rozenstajn L. Fibrinolytic treatment in thrombus on prosthetic heart valves. Br Heart J 1980;44:545-54.

10. Gagnon RM, Beaudet R, Lemire J. Streptokinase thrombolysis of chronically thrombosed mitral prosthetic valve. Cathet Cardiovasc Diagn 1984;10:5-10.

11. Ledain LD, Ohayon JP, Colle JP, Lorient-Roudaut FM, Roudaut RP, Besse PM. Acute thrombotic obstruction with disc prostheses: diagnostic considerations and fibrinolytic treatment. J Am Coll Cardiol 1986;7:743-51.

12. Kurzrok S, Singh AK, Most A, William DO. Thrombolytic therapy for prosthetic cardiac valve thrombosis. J Am Coll Cardiol 1987;9:592-8.

13. Graver LM, Gelber PM, Tyras DH. The risks and benefits of thrombolytic therapy in acute aortic and mitral prosthetic valve dysfunction: report of case and review of literature. Ann Thorac Surg 1988;46:85-8.

14. Martinell J, Jimenez A, Rabago G, Artiz V, Fraile J, Farre J. Mechanical cardiac valve thrombosis: Is thrombectomy justified? Circulation 1991;84:(Suppl):III70-5.

15. Roudaut R, Labbe T, Lorient-Roudaut MF, Gosse P, Baudet E, Fontan F, et al. Mechanical cardiac valve thrombosis: Is fibrinolysis justified? Circulation 1992;86(Suppl):II8-15.

16. Vassan RS, Kaul U, Sanghvi S. Thrombolytic therapy for prosthetic valve thrombosis: a study based on serial Doppler echocardiographic evaluation. Am Heart J 1992;123:1575-80.

17. Silber H, Khan SS, Matloff JM, Chaux A, DeRobertis M, Gray R. The St. Jude valve: thrombolysis as the first line of therapy for cardiac valve thrombosis. Circulation 1993;87:30-7.

18. Vitale N, Renzulli A, Cerasuolo F, Caruso A, Festa M, De Luca L, et al. Prosthetic valve obstruction: thrombolysis versus operation. Ann Thorac Surg 1994;57:365-70.

19. Reddy NK, Padmanabhan TNC, Singh S, Kumar DN, Raju PR, Satyanarayana PV, et al. Thrombolysis in left-sided prosthetic valve occlusion: immediate and follow-up results. Ann Thorac Surg 1994;58:462-71.

20. Koller PT, Arom KV. Thrombolytic therapy of left-sided prosthetic valve thrombosis. Chest 1995;108:1683-9.

21. Khandheria BK, Seward JB, Oh JK. Value and limitations of transesophageal echocardiography in assessment of mitral valve prostheses. Circulation 1991;83:1956-68.

22. Daniel WG, Mugge A, Grote J. Comparison of transthoracic and transesophageal echocardiography for detection of abnormalities of prosthetic and bioprosthetic valves in the mitral and aortic positions. Am J Cardiol 1993;71:210-5.

23. Acquired valvular heart disease. In: Feigenbaum H, editor. Echocardiography. 5th ed. Philadelphia: Lea \& Febiger; 1994. p. 239-349.

24. Kremer P, Ranier F, Tilsner V, Bleifeld W, Mahey DC. Lysis of ventricular thrombi with urokinase. Circulation 1985;72:112-8.

25. Gueret P, Vignon P, Fournier P, Chabernaud JM, Gomez M, LaCroix P, et al. Transesophageal echocardiography for the diagnosis and management of nonobstructive thrombosis of mechanical mitral valve prosthesis. Circulation 1995;91:103-10. 